\title{
Rancang Bangun Wireless Sensor Network Pada Pendeteksi Dini Potensi Kebakaran Lahan Gambut Menggunakan Banana Pi IoT
}

\author{
Hendra Irawan, Muhammad Rivai, dan Fajar Budiman \\ Departemen Teknik Elektro, Fakultas Teknologi Elektro, Institut Teknologi Sepuluh Nopember (ITS) \\ E-mail: hendra.irawan15@mhs.ee.its.ac.id,muhammad_rivai@ee.its.ac.id, fajarbudiman@ee.its.ac.id
}

\begin{abstract}
Abstrak - Lahan gambut merupakan bagian dari ekosistem yang banyak mengandung bahan organik yang tidak mudah terurai. Seringnya terjadi kebakaran lahan gambut membuat Indonesia kerap menderita kabut asap, sehingga diperlukan suatu sistem yang dapat mendeteksi potensi terjadinya kebakaran lahan gambut. Telah banyak penelitian tentang hal penanganan masalah tersebut, namun penelitian yang ditawarkan biasanya berupa pendeteksi paska kebakaran lahan gambut. Selain itu banyak teknologi yang ditawarkan mempunyai harga produksi yang mahal dan penggunaan daya yang tinggi. Sistem yang dirancang pada penelitian ini adalah penerapan Wireless Sensor Network menggunakan topologi tree pada pendeteksi dini potensi kebakaran lahan gambut yang diintegrasikan dengan Internet of Things. Menggunakan Arduino sebagai prosesor dari sensor node yang dibuat dan menggunakan Banana Pi sebagai server dari keseluruhan sitem. Sistem ini mengutamakan penanganan sebelum terjadinya kebakaran dengan membaca suhu lingkungan setiap node. Hasil dari sistem keseluruhan dapat dilihat pada tampilan halaman web yang dapat menampilkan informasi suhu permukaan lahan gambut. Jarak optimum peletakan antar node adalah $100 \mathrm{~m}$ dan kesuksesan membaca GPS mencapai $80 \%$.
\end{abstract}

Kata kunci-Banana Pi, Internet of Things, Lahan Gambut, Wireless Sensor Network.

\section{PENDAHULUAN}

L AHAN gambut adalah bagian dari ekosistem hutan tropis dengan tanah yang lembab dan banjir berkala hingga menghalangi kayu dan daun mati dari proses pembusukan. Dengan luas lahan 26 juta $\mathrm{Ha}$, Indonesia merupakan pemilik lahan gambut keempat terbesar di dunia setelah Amerika Serikat, Rusia, dan Kanada [1].

Namun, dengan potensinya yang besar, kebakaran lahan gambut menjadi hal yang sering terjadi di Indonesia. Setidaknya 2,6 juta Ha lahan gambut terbakar pada tahun 2015 yang menyebabkan kerugian hingga 221 triliun rupiah. Selain kerugian materil, terdapat juga kerugian non materil yang meliputi rusaknya habitat flora dan fauna, polusi yang mengganggu aktivitas, hingga masalah kesehatan [2].

Penyebab kebakaran gambut sangatlah beragam, mulai dari kesalahan manusia yaitu pembukaan lahan, pembuangan puntung rokok sembarangan, dan pembakaran sampah; faktor alam yaitu meliputi suhu yang tinggi, curah hujan yang sedikit, lahan yang mudah terbakar. Puncak kebakaran hutan terjadi pada saat musim kemarau dimana lahan mulai mengalami pengeringan, kelembaban udara sangat rendah dan suhu lahan tinggi. Pada kondisi tersebut sangat mudah terpicunya kebakaran pada lahan gambut [3].

Salah satu satelit yang dapat digunakan untuk memantau permukaan bumi adalah NOAA-AVHRR (National Oceanic and Atmospheric Administration - Advanced Very High Resolution Radiometer). Namun kelemahanya adalah resolusinya yang rendah yaitu $1 \mathrm{~km}$ sehingga tidak dapat mendeteksi kebakaran yang lebih kecil. Selain itu NOAA juga memiliki kelemahan berupa waktu pembacaan yang lama yaitu satu hingga dua hari untuk memperoleh informasi yang diinginkan [4]. Untuk itu maka diperlukan teknologi yang mampu beroperasi di wilayah yang luas, mampu bekerja secara mandiri serta dapat memberikan informasi secara akurat dan real time.

\section{TEORI PENUNJANG}

Pada umumnya kebakaran hutan dan lahan gambut bukan merupakan fenomena asing lagi di beberapa wilayah Indonesia, terutama Sumatera, Kalimantan dan Papua. Fenomena alam ini berkembang menjadi suatu bentuk bencana alam yang mempunyai dampak terhadap aspekaspek kehidupan masyarakat. Gambut adalah jenis tanah yang terbentuk dari akumulasi sisa-sisa tumbuhan yang setengah membusuk; oleh sebab itu, kandungan bahan organiknya tinggi. Sisa-sisa tumbuhan yang mengering membuat lahan gambut menjadi mudah terbakar.

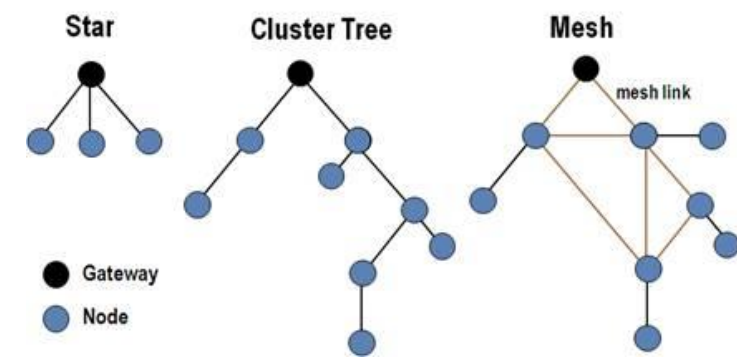

Gambar 1. Topologi Wireless Sensor Network.

\section{A. Wireless Sensor Network (WSN)}

Wireless Sensor Network atau sering disingkat dengan WSN adalah suatu peralatan sistem embedded yang berkomunikasi tanpa kabel yang di dalamnya terdapat satu atau lebih sensor dan dilengkapi dengan peralatan sistem komunikasi. Sensor di sini digunakan untuk menangkap informasi sesuai dengan karakteristik dan penyajian informasi melalui komunikasi internet. 
Dalam penggunaanya ada beberapa jenis topologi yang sering digunakan dalam WSN. Pemilihan topologi bertujuan menyesuaikan kebutuhan dan medan penempatan jaringan. Adapun beberapa topologi jaringan yang umum digunakan dalam pembangunan sebuah sistem WSN adalah topologi star, cluster/tree, dan mash. Bentuk topologi WSN dapat dilihat pada Gambar 1.

Arsitektur topologi cluster/tree lebih komplek dibanding dengan topologi star. Setiap node masih mempertahankan satu jalur komunikasi untuk gateway. Pengiriman data dapat dilakukan melalui node-node router, namun masih dalam satu jalur tersebut [4].

\section{B. Internet of Things}

Secara umum Internet of Things (IoT) adalah suatu konsep menghubungkan perangkat pintar dengan perangkat pintar yang lain baik digunakan untuk bertukar data maupun untuk keperluan pengendalian melalui internet. Saat ini konsep IoT sudah banyak digunakan pada objek di sekitar kita. Diperkirakan pada tahun 2020 dala 50 miliar objek yang terhubung dengan Internet.

Meski telah digunakan pada banyak perangkat untuk menunjang kehidupan sehari-hari, Internet of Things belum memiliki definisi yang baku. Namun secara sederhana konsep Internet of thing dapat dilihat pada Gambar 2 [5].

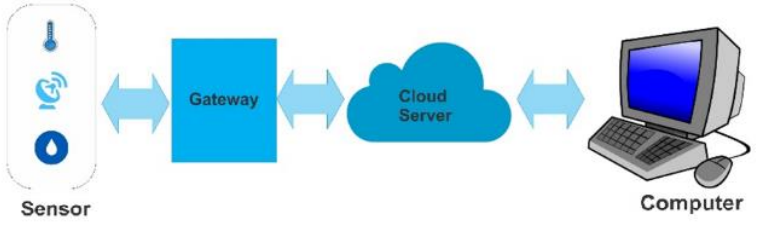

Gambar 2. Blok Sistem IoT.

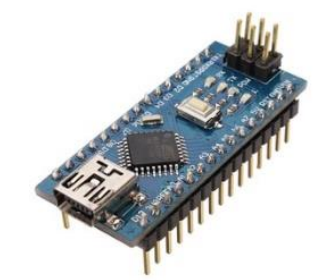

Gambar 3. Arduino Nano.

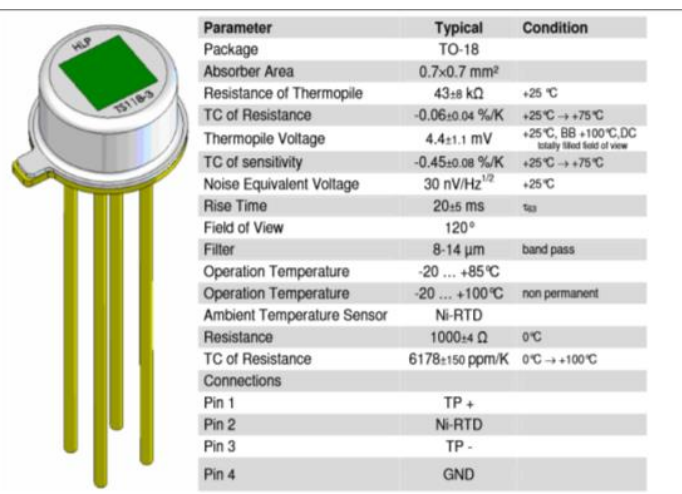

Gambar 4. Sensor Suhu TS118-3.

\section{Arduino Nano}

Arduino Nano seperti pada Gambar 3 adalah papan pengembangan (development board) mikrokontroler yang berbasis chip ATmega328P. Arduino Nano memiliki 14 buah digital pin yang dapat digunakan sebagai input atau output. Pin-pin tersebut bekerja pada tegangan $5 \mathrm{~V}$, dan setiap pin dapat menyediakan atau menerima arus $20 \mathrm{~mA}$, dan memiliki resistor pull-up sekitar 20-50k ohm. Arduino sendiri didukung dengan IDE pemrogramannya dengan bahasa pemrograman C. IDE pada Arduino dapat sangat membantu dari proses pemrograman karena sangat mudah dalam pengoprasianya [6].

\section{Thermopile TS188-3}

Thermopile adalah sensor suhu yang digunakan untuk mengukur suhu dengan tidak menyentuh langsung (contactless) objek pengukuran. Thermopile bekerja dengan merubah radiasi panas yang dipancarkan benda kedalam bentuk tegangan.

Pada tipe TS188-3 memiliki suhu kerja $-20^{\circ} \mathrm{C}$ sampai dengan $100^{\circ} \mathrm{C}$ dengan karakteristik output $-0,6 \mathrm{mV}$ sampai dengan $4,4 \mathrm{mV}$, dengan resistansi sensor $1000 \Omega$ pada suhu $0^{\circ} \mathrm{C}$. TS188-3 memiliki empat buah pin yang mana pin 1 merupakan $\mathrm{TP}+$, pin 2 merupakan Ni-RTD, pin 3 merupakan TP-, dan pin 4 merupakan ground. Gambar 4 merupakan bentuk dari thermopile TS188-3 [7].

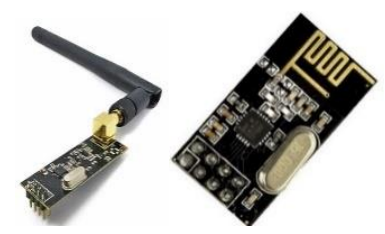

Gambar 5. Modul nRF24L01[8]

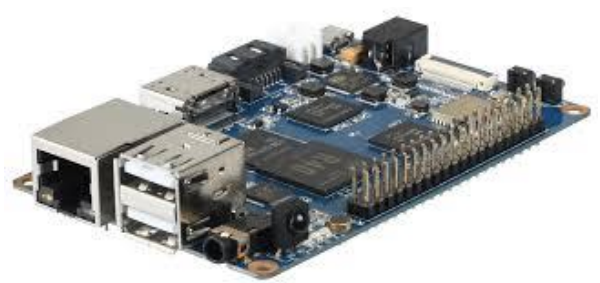

Gambar 6. Banana Pi

\section{E. Radio Frequency}

Modul Radio Frekuensi nRF24L01 adalah sebuah modul komunikasi jarak jauh yang memanfaatkan pita gelombang RF $2.4 \mathrm{GHz}$ ISM (Industrial, Scientific and Medical). Modul ini menggunakan antar muka SPI untuk berkomunikasi. Modul nRF24L01 seperti yang ditunjukkan pada Gambar 5 memiliki base brand logic Enhanced Shock Burst dengan hardware protocol accelerator yang support "high-speed SPI interface for the application controller". Modul ini memiliki true UTP solution, yang memungkinkan daya baterai bertahan hingga berbulan-bulan hingga bertahun-tahun [8].

\section{F. Banana Pi M2U}

Banana Pi M2U seperti yang ditunjukkan pada Gambar 6 adalah Board berukuran kecil yang memiliki konsumsi daya rendah. Dengan menggunakan prosesor Quad core dan RAM 2 GB membuat Banana Pi M2U sangat baik digunakan untuk pemrosesan data yang berat. Selain itu, Banana Pi M2U dilengkapi juga dengan WiFi yang mempermudah melakukan koneksi ke internet. OS Banana 
Pi kompatibel dengan Android KitKat, Resbian, Ubuntu, dan lain-lain.

Banana Pi M2U dilengkapi dengan General-Purpose Input/Output (GPIO) yang mempermudah dalam pemrosesan input-output pada Banana Pi. Pada GPIO terdapat port-port unik yang dapat digunakan, mulai dari pin I/O, pin ADC, pin serial dan pin Power[9].

\section{PERANCANGAN SISTEM}

Pada penelitian ini telah dirancang sebuah sistem yang terdiri dari 5 buah node dan 1 buah webserver, ditunjukan oleh Gambar 7. Teknologi Wireless Sensor Network (WSN) dan Internet of Thing (IoT) digunakan untuk mengkomunikasikan data antar sensor/ node agar data dapat diterima oleh server dan kemudian di simpan pada cloud lalu dapat diakses melalui internet.

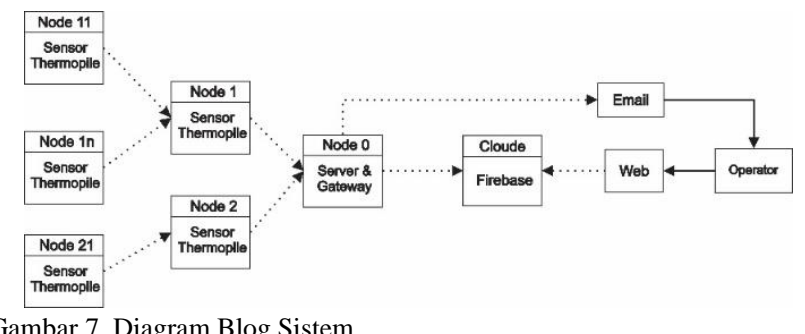

Gambar 7. Diagram Blog Sistem.

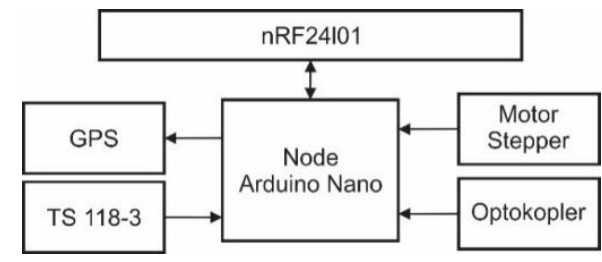

Gambar 8. Diagram Blog Sensor.

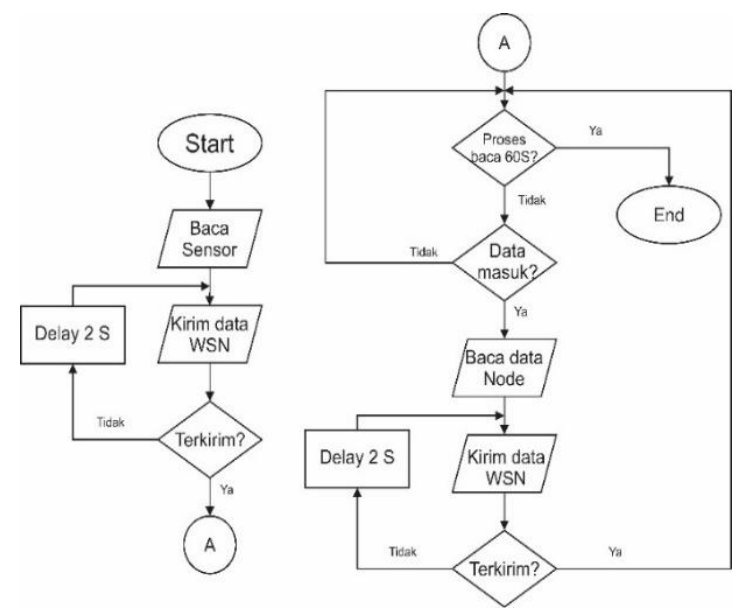

Gambar 9. Blok diagram pada sensor node.

Dengan teknologi WSN dan IoT diharapkan sensor dapat disebar pada area yang luas untuk memberikan informasi tentang potensi kebakaran lahan gambut.

\section{A. Sistem Sensor Node}

Sensor node adalah perangkat yang berfungsi untuk mengambil data suhu lahan gambut dan digunakan untuk mengirimkan data-data sensor node ke server. Selain itu untuk menunjang sistem Wireless Sensor Network, sensor node berfungsi sebagai perantara sensor node yang lain untuk mengirimkan datanya menuju server. Penyusunan blok-blok fungsional pada sistem untuk menghasilkan sistem sensor node dapat dilihat pada Gambar 8. Diagram alir dari sensor node dapat dilihat pada Gambar 9.

Modul ini akan terintegrasi dengan sistem dengan mendeklarasikan alamat node dan kanal yang digunakan. Karena sistem yang digunakan adalah Wireless Sensor Network dengan topologi tree sehingga perlu untuk mengetahui alamat yang hendak dituju. Pendeklarasian alamat dan algoritma alamat yang dituju dideklarasikan di awal pemrograman dari sistem.

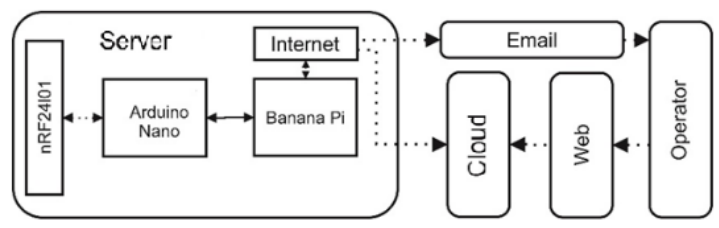

Gambar 10. Diagram Blog Server.

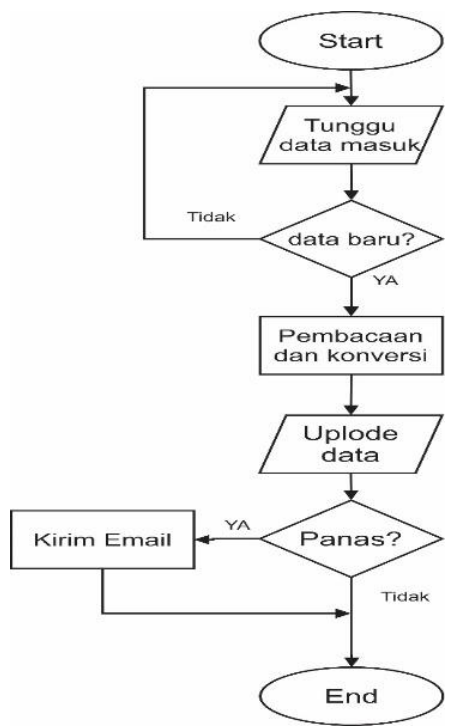

Gambar 11. Diagram Alir Perancangan Sistem.

Untuk pembacaan suhu di sekitar sensor node menggunakan thermopile dan dibantu dengan gerakan mekanik dari motor stepper. Sedangkan untuk menentukan sudut pembacaan menggunakan bantuan sensor optokopler dan cakram.

\section{B. Sistem Server}

Server merupakan perangkat yang akan digunakan sebagai kontrol data yang dikirim oleh node melalui jaringan WSN. Perangkan ini akan mengirimkan data dari sensor node menuju cloud dan mengirimkan pesan berupa Email pada operator bila terjadi gangguan. Blok fungsional yang disusun untuk membuat sistem server ditunjukkan pada Gambar 10.

Diagram alir sistem server dapat dilihat pada Gambar 11. Pada bagian server yang perlu diperhatikan adalah jaringan internet yang digunakan untuk mengirimkan data ke sistem cloud serta mengirim email pada saat terdeteksi terjadinya panas pada titik tertentu. Data grafik yang mewakili suhu permukaan lahan gambut akan ditampilkan pada halaman 
website yang dapat diakses menggunakan browser yang mendukung HTML5, seperti Mozila Firefox.

\section{HASIL PENGUJIAN}

Pada Gambar 12 merupakan bentuk dari sistem Sensor Node sedangkan pada Gambar 13 merupakan bentuk dari Server pada sistem yang dibuat.

1. Pengujian Catu Daya pada Sensor Node

Pada Tabel 1 menunjukkan hasil pengukuran daya ratarata sebesar 6.57 watt dalam perioda waktu 40 detik.

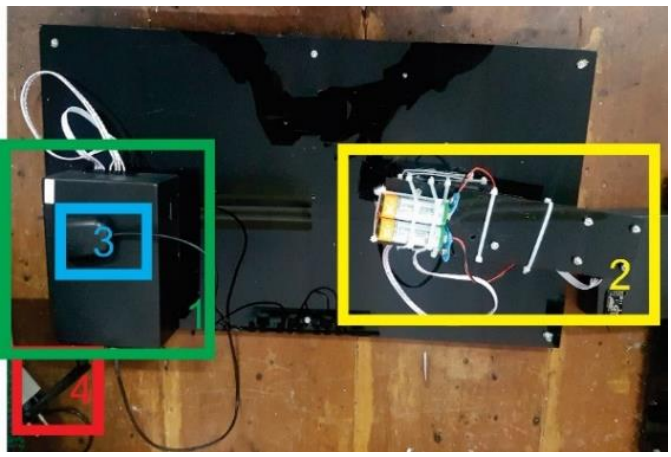

Gambar 12. Bentuk Sistem yang Dibuat.

Keterangan: 1) Kotak kontrol Node, 2) Sensor Suhu 3) Antena GPS, dan 4) Antena nRF24L01.

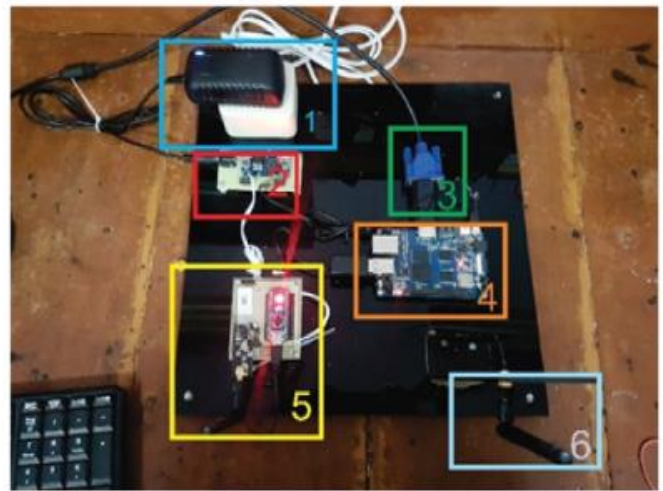

Gambar 13. Server dari Sistem yang Dibuat.

Tabel 1.

Hasil Pengukuran Daya

\begin{tabular}{|c|c|c|c|c|c|c|c|}
\hline \multirow{2}{*}{ No } & \multicolumn{3}{|c|}{ Saat Standby } & \multicolumn{3}{|c|}{ Saat Aktif } & \multirow{2}{*}{$\begin{array}{l}P_{\text {rata }} \\
\text { (W) }\end{array}$} \\
\hline & $\mathrm{I}(\mathrm{A})$ & $\mathrm{V}(\mathrm{V})$ & $\mathrm{P}_{\mathrm{S}}(\mathrm{W})$ & $\mathrm{I}(\mathrm{A})$ & $\mathrm{V}(\mathrm{V})$ & $\mathrm{P}_{\mathrm{A}}(\mathrm{W})$ & \\
\hline 1 & 0.57 & 11.3 & 6.4 & 0.64 & 11.3 & 7.2 & 6.57 \\
\hline 2 & 0.56 & 11.3 & 6.3 & 0.65 & 11.3 & 7.3 & 6.49 \\
\hline 3 & 0.59 & 11.3 & 6.6 & 0.66 & 11.3 & 7.4 & 6.79 \\
\hline 4 & 0.55 & 11.3 & 6.2 & 0.64 & 11.3 & 7.2 & 6.38 \\
\hline 5 & 0.57 & 11.3 & 6.4 & 0.64 & 11.3 & 7.2 & 6.57 \\
\hline 6 & 0.58 & 11.3 & 6.5 & 0.64 & 11.3 & 7.2 & 6.67 \\
\hline \multicolumn{7}{|c|}{ Daya Rata-Rata } & 6.57 \\
\hline
\end{tabular}

2. Pengujian Sensor Suhu

Pada pengujian kalibrasi diperoleh data pada Tabel 2 dan Gambar 14. Kurva persamaan yang telah diperoleh akan digunakan untuk pemrograman Arduino, dinyatakan:

$$
y=0.0033 x^{2}+0.5899 x+135.23
$$

Tabel 2.

Data Pengukuran Suhu

\begin{tabular}{|c|c|c|c|}
\hline \multicolumn{2}{|c|}{$\mathrm{ADC}$} & \multirow{2}{*}{$\begin{array}{l}\text { Jarak Objek ke } \\
\text { Sensor }(\mathrm{cm})\end{array}$} & \multirow{2}{*}{$\begin{array}{c}\text { Suhu Terbaca } \\
\left({ }^{\circ} \mathrm{C}\right)\end{array}$} \\
\hline Thermopile & Thermistor & & \\
\hline 155 & 559 & 10 & 30 \\
\hline 164 & 559 & 10 & 40 \\
\hline 173 & 559 & 10 & 50 \\
\hline 187 & 559 & 10 & 60 \\
\hline 190 & 559 & 10 & 70 \\
\hline 202 & 599 & 10 & 80 \\
\hline 213 & 599 & 10 & 90 \\
\hline 229 & 599 & 10 & 100 \\
\hline
\end{tabular}

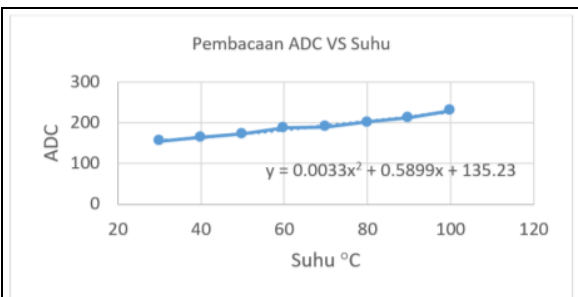

Gambar 14. Grafik Pembacaan Sensor Suhu.

Tabel 3.

Hasil Percobaan Pengiriman Data

\begin{tabular}{|c|c|c|c|}
\hline \multirow{2}{*}{ Jarak $(\mathrm{m})$} & \multicolumn{3}{|c|}{ Respon } \\
\cline { 2 - 4 } & Percobaan 1 & Percobaan 2 & Percobaan 3 \\
\hline 10 & Bisa & Bisa & Bisa \\
\hline 20 & Bisa & Tidak Bisa & Bisa \\
\hline 30 & Bisa & Bisa & Bisa \\
\hline 40 & Tidak Bisa & Bisa & Bisa \\
\hline 50 & Bisa & Bisa & Bisa \\
\hline 60 & Bisa & Tidak Bisa & Bisa \\
\hline 70 & Bisa & Bisa & Bisa \\
\hline 100 & Bisa & Bisa & Bisa \\
\hline 150 & Tidak Bisa & Tidak Bisa & Tidak Bisa \\
\hline \multicolumn{4}{|c}{} \\
\hline
\end{tabular}

Tabel 4.

Pengambilan Data GPS

\begin{tabular}{|r|r|r|r|}
\hline No & \multicolumn{1}{|c|}{$\begin{array}{c}\text { Latitude } \\
\text { (Lintang) }\end{array}$} & \multicolumn{1}{c|}{$\begin{array}{c}\text { Longitude } \\
\text { (Bujur) }\end{array}$} & \multicolumn{1}{c|}{$\begin{array}{c}\text { Meters } \\
\text { (MDPL) }\end{array}$} \\
\hline 1 & 0 & 0 & 0 \\
\hline 2 & 0 & 0 & 0 \\
\hline 3 & -7.28 & 112.8 & -13.7 \\
\hline 4 & -7.28 & 112.8 & -13.7 \\
\hline 5 & -7.28 & 112.8 & -13.5 \\
\hline 6 & -7.28 & 112.8 & -13.7 \\
\hline 7 & -7.28 & 112.8 & -13.5 \\
\hline 8 & -7.28 & 112.8 & -13.6 \\
\hline 9 & -7.28 & 112.8 & -13.7 \\
\hline 10 & -7.28 & 112.8 & $80 \%$ \\
\hline \multicolumn{4}{|r|}{ Persentase Keberhasilan $=8$} \\
\hline
\end{tabular}

3. Pengujian Jarak sensor node

Percobaan dilakukan pada wilayah terbuka tanpa halangan antar node. Tabel 3 merupakan hasil dari pengukuran jarak antar node. Dapat dilihat bahwa komunikasi terjauh yang dapat dilakukan adalah $100 \mathrm{~m}$. Pada percobaan ini masih terdapat beberapa kali error data namun pengiriman tetap dapat dilakukan pada saat pengiriman kedua atau ketiga.

4. Pengujian GPS

Pengujian dilakukan pada ruangan laboratorium yang ditunjukkan pada Tabel 4. Terdapat beberapa kali sensor node tidak dapat mengakses koordinat lokasi. Hal tersebut dikarenakan lokasi pengujian dilakukan pada ruangan tertutup, sehingga menghalangi dari pembacaan 
koordinat sensor yang dipasang. Persenstase keberhasilan pembacaan GPS adalah $80 \%$.

\section{A. Pengujian Internet of Things}

Hasil dari sistem keseluruhan dapat dilihat dengan mengunjungi http://pantauanpanas.esy.es/. Hasil dari pengujian pembacaan suhu permukaan lahan yang ditampilkan di websit dapat dilihat pada Gambar 15. Gambar 16 merupakan contoh email yang dikirim dengan alamat hendrairawan160194@gmail.com.

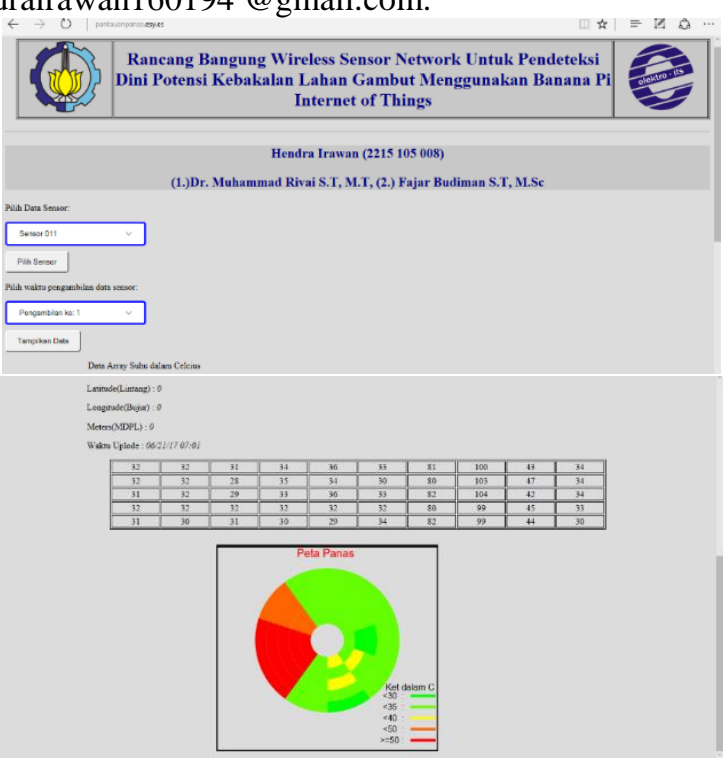

Gambar 15. Tampilan Web.

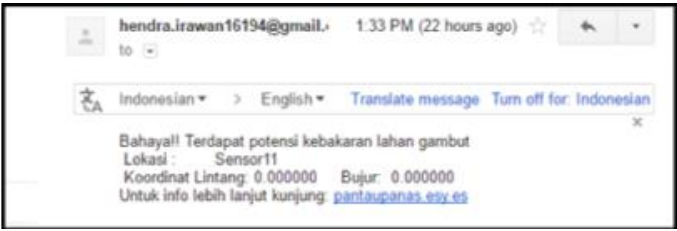

Gambar 16. Email Masuk Kepada Operator.

\section{KESIMPULAN}

Pada penelitian ini telah dilakukan rancang bangun wireless sensor network pada pendeteksi dini potensi kebakaran lahan gambut menggunakan Banana Pi IoT. Penerapan jaringan WSN yang dirancang menggunakan Arduino dan nRF24L01 dengan topologi tree. Hasil pengujian menunjukkan bahwa konsumsi daya pada sistem sensor node rata-rata adalah 6,57 W. Jarak maksimum antar node dapat mencapai $100 \mathrm{~m}$. Pembacaan GPS dapat diakses dengan baik dan sesuai dengan kebutuhan dari sistem dengan persentase keberhasilan mencapai $80 \%$. sangat relevan dengan dengan kemampuan dan kapasitas komponen. Perancangan website didasarkan dengan interface yang mudah dan dapat dimengerti yaitu berupa tampilan profil suhu permukaan yang diwakili dengan intensitas warna.

\section{DAFTAR PUSTAKA}

[1] Pengelolaan Lahan Gambut. Kelompok Kerja Pengelolahan Lahan Gambut Nasional, 2006.

[2] A. Akbar and S. Faidil, "Kebakaran hutan dan lahan rawa gambut: penyebab faktor pendukung dan alternatif pengelolaannya," pp. 1-18, 2013.

[3] F. L. Box, "Kebakaran Lahan Gambut, Penyakit Menahun Indonesia - Lingkungan," pp. 4-7, 2016.

[4] and E. H. P. M. Y. Hariyawan, A. Gunawan, "Implementasi Wireless Sensor Network untuk Pendeteksi Dini Kebakaran Hutan," vol. 5, pp. 1-10.

[5] E. D. Meutia, J. Teknik, E. Universitas, and S. Kuala, "Internet of Things - Keamanan dan Privasi," Semin. Nas. dan Expo Tek. Elektro 2015, pp. 85-89, 2015.

[6] U. Manual, "Arduino Nano."

[7] Measurment Specialties, "Thermopile Sensor TS118-3," no. June, pp. 1-2, 2007.

[8] Nordic Semiconductor, "nRF24L01 Single Chip 2 . 4GHz Transceiver Product Specification,” no. July, 2007.

[9] Banana Pi, "What is Banana Pi M2 Ultra?," Banana Pi. 